\title{
Construyendo la identidad nacional desde la derrota: Alianza Lima y su eliminación de la Copa Libertadores 2010
}

Alonso Pahuacho*

* Licenciado en Periodismo y Magíster en Estudios Culturales por la Pontificia Universidad Católica del Perú. Actualmente se desempeña como docente en las facultades de Estudios Generales Letras y Ciencias y Artes de la Comunicación en dicha casa de estudios. Correo electrónico: apahuacho@pucp. pe. Código Orcid: https://orcid.org/0000-0001-8783-7978

Fecha de recepción: 01/04/2020. Fecha de aceptación: 06/05/2020. 
Construyendo la identidad nacional desde la derrota: Alianza Lima y su eliminación de la Copa Libertadores 2010

\title{
Resumen
}

El objetivo de este artículo es analizar el tratamiento informativo de la prensa deportiva con respecto a la construcción de la identidad nacional peruana en el contexto de una derrota deportiva en una competición internacional. La forma en que se construyó un nacionalismo deportivo (Panfichi, 2017) por los medios de prensa puede usarse como un lente a través del cual examinar cómo elementos de la identidad fueron reproducidos, reforzados y esencializados por la prensa a través de la cobertura del club Alianza Lima en su campaña en la Copa Libertadores 2010. Por medio del Análisis Crítico del Discurso (ACD), la pesquisa revela que, luego de la eliminación del equipo peruano, la prensa deportiva terminó por construir un relato entre lo fantástico y lo mítico del asunto: atribuyó la eliminación a factores externos (robo arbitral) y la dignificó a modo de gesta épica.

Palabras clave: identidad nacional, Perú, Chile, fútbol, periodismo deportivo.

\section{Shaping national identity through loss: Alianza Lima and its elimination from Copa Libertadores 2010}

\begin{abstract}
The aim of this article is to investigate the role played by the printed press in the construction of Peruvian national identity within the context of sporting loss in an international competition. Media representation of Peruvian sporting nationalism can be used as a lens through which to examine how elements of the national identity were represented, reproduced and reinforced by the media following the Alianza Lima soccer team's performance. Through the Critical Discourse Analysis (CDA), this research reveals that after the elimination of the Peruvian team, the printed press constructed the failure since a double perspective: attribute the defeat due to external factors (blaming the referee) and dignify it as an epic deed.
\end{abstract}

Keywords: national identity, Perú, Chile, football, sport journalism. 


\section{INTRODUCCIÓN}

Hoy en día resulta poco convincente argumentar en contra de la idea de que el deporte es altamente eficaz para contribuir a la formación de la identidad nacional (Rowe, 2004). El deporte internacional, en particular, ha demostrado ser un contribuyente exitoso en la formación de un sentido de pertenencia nacional que, ciertamente, resulta algo artificial, ya que en ocasiones se suelen pasar por alto las diferencias de clase, género, étnicas o regionales. Es a través del discurso de los medios de comunicación que la propia identidad nacional colectiva se promueve y las de los demás se discuten, mientras la nación rivaliza frente a otra en una guerra simbólica en un rectángulo verde.

Por lo tanto, el deporte globalizado puede proporcionar un escenario para la perpetuación de las relaciones con los «otros», a menudo ayudadas por la propagación de ciertos esquemas lingüísticos y narrativos adoptados y utilizados para enfatizar la diferencia entre «nosotros» y «ellos». En efecto, Elías ha sugerido que los encuentros deportivos internacionales han llegado a servir «como representaciones simbólicas de una forma no violenta o no militar de competencia entre Estados nacionales» (1992, p. 36). En consecuencia, el éxito deportivo o la derrota ha llegado a ser visto como indicativo de la superioridad o inferioridad de una nación en el esquema más amplio y global de las cosas, lo que se considera que refleja la posición de una nación en la jerarquía mundial de los Estados. En el contexto sudamericano, esta apreciación se torna especialmente relevante, tomando en cuenta la cantidad de países de la región (solo diez), sumado al hecho de que la gran mayoría de ellos concibió al deporte — desde su adopción a inicios del siglo XX — precisamente como una de las vías de alcanzar fama y prestigio internacional.

En este sentido, paralelamente, podríamos advertir que el deporte también actúa simbólicamente como una suerte de canal para la "gestación» de un sentido de resentimiento colectivo. Las hostilidades históricas o contemporáneas a menudo encuentran su expresión más álgida en las competiciones deportivas, tal como están retratadas por los medios de comunicación, y proporcionan a las naciones una vía accesible y «legítima» — fuera del dominio político— para "emparejar el marcador». Como observa Bromberger (1994, p. 284), «cada enfrentamiento entre ciudades, regiones y países rivales toma la forma de una guerra ritualizada, que se complementa con la ceremonia de himnos, las bandas o desfiles militares y banderolas de los fanáticos». De esta manera, el deporte puede expresar —e incluso reforzar- las divisiones y tensiones internacionales ${ }^{1}$.

\footnotetext{
Basta recordar la rivalidad entre EE. UU. y la Unión Soviética en el contexto de la Guerra Fría, la cual tuvo impactos tangibles en el vector deportivo.
} 
En la actualidad, podría decirse que el deporte peruano goza de buena salud. $\mathrm{O}$, en todo caso, marcha mejor que antes. Acabamos de ser sede de los Juegos Panamericanos y Parapanamericanos — donde el Perú marcó un récord al obtener 41 medallas - y la selección masculina logró la clasificación al Mundial de Rusia 2018 tras 36 años de ausencia. Pero tan solo una década atrás las cosas eran muy distintas. En julio de 2011, el diario El Comercio publicó una encuesta elaborada por Ipsos-Apoyo en un suplemento especial dedicado a las Fiestas Patrias del Perú. A la pregunta: «¿Cuáles son las razones por las que usted se siente orgulloso de ser peruano?», la mayoría de los encuestados se decantaron por alternativas como música (19\%), gastronomía (41\%), cultura milenaria (38\%), recursos naturales (45\%) o Machu Picchu, que obtuvo el $56 \%$ de las preferencias quedando en el primer lugar de la lista. Muy relegado, incluso atrás del voley (12\%), quedó el fútbol, con solo el $6 \%$ del gusto popular (undécimo lugar). Habría que precisar, desde luego, que por aquellos años el contexto no era el más idóneo para el balompié nacional: Perú había terminado último en las eliminatorias para el Mundial de Sudáfrica 2010. Precisamente el sociólogo Aldo Panfichi, comentando dicha encuesta, afirmaba que lo que se necesitaba por aquellos años eran triunfos deportivos para que los peruanos se sintieran «realmente felices» ${ }^{2}$.

No obstante dicho panorama sombrío, a finales de aquella década el fútbol seguía siendo el deporte más popular del Perú, y prueba de ello era la consolidación de una prensa especializada en deportes en el país con la llegada de un nuevo jugador al mercado editorial (Depor, del grupo El Comercio) a inicios de 2009, con lo que el número de diarios especializados en información deportiva se elevó hasta cuatro, siendo hasta la fecha el país con mayor oferta periodística en este rubro en toda la región. Además de contar con numerosos programas deportivos en televisión por cable y señal abierta, así como a través de la radio como la conocida señal de Ovación. Como lo hemos sostenido anteriormente (Pahuacho, 2014), es esta prensa deportiva la que, desde sus páginas, siempre ha acompañado las campañas tanto de la selección nacional como la de cualquier equipo peruano que haya participado en los torneos oficiales de la Conmebol. Todo ello, volvemos a insistir, a pesar de nuestros escasos éxitos deportivos por aquellos tiempos.

Ahora bien, en el caso de torneos como la Copa Libertadores o la Copa Sudamericana, ciertamente la participación de nuestros representantes se ha convertido en una pesadilla de verano, una de la que los peruanos queremos rápidamente despertar, salvo contadas excepciones ${ }^{3}$. En este trabajo en particular, presentamos un

\footnotetext{
2 Ipsos Apoyo Opinión y Mercado. Mucho más orgullosos que antes. Encuesta realiza a pedido del diario El Comercio, 31 de julio de 2011.

3 Desde luego, debemos recordar las actuaciones del club cusqueño Cienciano, que en la década pasada se convirtió en el primer club peruano en conquistar un título internacional (Copa
} 
análisis de lo que quizá haya sido la última campaña destacada en la Copa Libertadores de uno de los clubes de más tradición en el fútbol peruano: el Alianza Lima. En el año 2010, los Íntimos, como también se les conoce, lograron acceder a la segunda fase de dicho torneo (octavos de final), donde terminaron eliminados por la Universidad de Chile tras empatar en el partido de vuelta disputado en Santiago 2-2. Pero quedaron fuera debido a que habían caído en la ida jugada en Lima por 0-1. La desazón en la prensa peruana fue grande, ya que, en el partido definitorio en Santiago, el equipo aliancista estuvo arriba en el marcador por 1-2 en gran parte del partido, resultado que le hubiese otorgado la clasificación debido a la regla del gol de visita ${ }^{4}$.

Hasta que llegó la jugada del gol del empate chileno (autogol aliancista en realidad), la cual desató la polémica y generó la construcción toda una serie de narrativas nacionalistas y contenciosas en los medios de comunicación deportivos peruanos. En ese sentido, nuestro objetivo es, precisamente, investigar el uso de fútbol para crear, configurar y reforzar la identidad nacional peruana en el contexto de la derrota del Alianza Lima en este partido de la Copa Libertadores frente a la Universidad de Chile. Para lograr ello, nos centraremos en la forma en que la información futbolística se utilizó para fomentar ciertos mitos, clichés y estereotipos asociados con los rivales chilenos.

\section{FÚTBOL, IDENTIDAD Y NACIÓN: CONSIDERACIONES TEÓRICAS}

Cualquier discusión sobre el fútbol peruano debe necesariamente tomar en cuenta las narrativas sobre la idea de «lo nacional» en el Perú. En la actualidad, el país es reconocido mundialmente por su historia (los incas), su gastronomía, su diversidad cultural y su literatura (con un premio Nobel incluido), mas no necesariamente por la potencia de su fútbol. Sin embargo, su presencia se manifiesta en nuestra vida cotidiana casi como algo intrínseco. Wood, en ese sentido, apunta que «el fútbol en el Perú sirve para revelar las ambigüedades e indeterminaciones de la historia cultural del país y, hasta cierto punto, ayuda a resolverlas: si bien se define en parte por

\footnotetext{
Sudamericana 2003), y al año siguiente, la Recopa. Este dato no es menos, pues se impuso en sendas finales a los prestigiosos clubes argentinos River Plate y Boca Juniors, respectivamente.

4 A partir de la ronda de octavos, los emparejamientos entre los equipos son en llaves de eliminación directa, es decir, en partidos de ida y vuelta. Alianza Lima jugó de local el primer partido en Lima y perdió 0-1. Ateniéndose a las reglas de la Copa que priorizan los goles de visitante, la única posibilidad de clasificación directa para el equipo peruano era anotar dos goles en Santiago o ganar por el mismo marcador para forzar los penales. Así, por ejemplo, si el partido hubiese quedado 1-2 en favor de los peruanos, serían estos últimos los que hubiesen clasificado por la cantidad de goles anotados como visitante y no por la diferencia de goles, que sería la misma sumados ambos encuentros (2-2). Como el partido terminó 2-2, clasificó la Universidad de Chile con un marcador global de 3-2 a su favor.
} 
la cultura nacional dominante, al mismo tiempo realiza una contribución importante al definir y refinar lo que significa ser peruano» (2008, p. 248).

Podemos establecer el vínculo entre fútbol y nación en el Perú a partir de dos factores. El primero es la popularidad que tiene el balompié en nuestro país y la masividad con la que es practicado. En efecto, el Instituto de Estudios Peruanos (2019) realizó una encuesta sobre Peruanidad y Bicentenario que se publicó con motivo de las Fiestas Patrias de 2019. A la pregunta "¿Qué creemos que nos une?», la respuesta que obtuvo la mayoría de votos fue «El deporte», con el $47 \%$, por encima de otros elementos, como la gastronomía, cultura o historia.

En segundo lugar, y siguiendo a Villena, el fútbol también puede funcionar como un generador de profundos rituales de reforzamiento del sentido de pertenencia nacional. Según este autor, quien entiende al ritual como un «modo de conducta colectiva de carácter simbólico, que se repite regularmente con el fin de dotar de sentido de trascendencia comunitaria a los miembros de la comunidad» (1998, p. 96), el fútbol presenta una serie de condiciones internas favorables para ser la representación de una nación. ¿Cuáles serían estas condiciones favorables? Villena menciona las competencias deportivas internacionales, las cuales son vividas por las poblaciones interpeladas como verdaderos duelos entre naciones.

Con el fin de dejar en claro esta ligazón, nos guiamos bajo la perspectiva de entender a la nación como una forma de narración (Bhabha, 2010). En las últimas décadas, esta idea ha cobrado gran relevancia en el ámbito académico, particularmente desde los Estudios Culturales. Trabajar sobre esta idea implica ocuparse necesariamente de los distintos tipos de historias que las diferentes instituciones cuentan sobre los orígenes de cada una de ellas. Y para el caso de nuestro análisis, consideramos a la prensa escrita como una de esas instituciones capaces de "contar» la historia de una nación desde el ámbito del deporte, el cual también construye y reconstruye sus propias prácticas, historias, metáforas, imágenes, mitos y tradiciones inventadas. Así, coincidimos con Quiroga cuando postula que «las crónicas y los reportajes deportivos se convirtieron en una forma adicional de hablar sobre la nación. Al igual que en los casos de la literatura, la música y el cine, la escritura deportiva adquirió un carácter nacionalizador al atribuir aspectos patrios a los atletas y a los equipos» (2014, p. 23).

Teóricos clásicos y modernos del nacionalismo, afines a la propuesta de pensar la nación como una forma de narración, parecen comulgar con la posibilidad de imaginar una identidad nacional a partir del fútbol, aun cuando no hayan mencionado exclusivamente a este deporte dentro de su vasta bibliografía. Hobsbawm (1990, p. 43) lo expresa de la siguiente manera: «la comunidad imaginada de millones de seres parece más real bajo la forma de un equipo de once personas cuyo nombre conocemos». Conceptos tan abstractos como "comunidad nacional», o incluso el 
de "nación», se tornan visibles a través de una camiseta y miles de hinchas dentro de un estadio entonando a todo pulmón el himno de su país. De ello podemos postular la siguiente idea: el fútbol, a través de los discursos periodísticos deportivos, es también un dispositivo que imagina a la nación peruana.

Por su parte, Benedict Anderson también adopta una serie de suposiciones sobre la cultura en su famosa noción de que la nación puede considerarse una «comunidad imaginada», unida por un "compańerismo profundo y horizontal» (1993, p. 25) por la cual se cree que los compañeros nacionales constituyen un límite, una entidad «natural». Mientras que algunos teóricos como Chatterjee (2007) se han quejado de que el enfoque de Anderson en lo imaginado parece ignorar las realidades sociopolíticas del poder y las estructuras organizativas del Estado, quizás una comprensión más matizada sea considerar que las naciones emergen de contextos de experiencias sociales y culturales que se conciben imaginativamente.

La clave del argumento de Anderson es la invención de la imprenta y el posterior aumento de los medios impresos, que proporcionaron un medio tecnológico para la difusión generalizada de la idea de la nación. Anderson comenta que la lectura compartida periódica y sincrónica del periódico diario o semanal produjo la idea de que los lectores compartían un conjunto de intereses (el contenido y el enfoque de las noticias, por ejemplo) en los que se los abordaba de manera explícita e implícita como co-nacionales. La experiencia nacional tiene sus raíces en lo cotidiano, ya que, como él dice, el periódico refuerza la suposición de que «el mundo imaginado está visiblemente enraizado en la vida cotidiana» (p. 61). Esto es muy sugerente. En lugar de las exhibiciones periódicas de espectáculos, la puesta en escena de la tradición y el impulso académico de clasificar las razas, las costumbres y la naturaleza, este proceso cultural opera en un nivel más mundano. La idea de lo que constituye el interés «nacional» es parte de lo que fundamenta la identidad nacional en formas irreflexivas de «sentido común».

Sin duda, los postulados de Anderson marcaron un hito dentro de las teorías de los nacionalismos contemporáneos. Sin embargo, su enfoque excesivo en la alfabetización y los medios impresos ofrece una visión reductiva de la cultura. Si bien la importancia histórica de la imprenta es notable, es curioso que no se haga referencia a las múltiples formas en que se imaginan a la nación, por ejemplo, el teatro, la música popular, festividades, arquitectura, moda, espacios de congregación y toda una plenitud de hábitos y actuaciones encarnadas, sin mencionar formas culturales más paralelas, como la televisión, el cine, la radio y la tecnología de la información. $\mathrm{Y}$, desde luego, el deporte, encarnado en su máxima expresión, que es el fútbol.

En un plano local, académicos como Panfichi (2017) han postulado el concepto de «nacionalismo deportivo» para referirse a «aquellos sentimientos patrióticos que cohesionan y crean vínculos afectivos de pertenencia a una misma comunidad polí- 
tica». Estos vínculos afectivos, señala el sociólogo, serían proclives a despertarse en los torneos internacionales, donde la competencia entre países se pone de manifiesto: «[El] nacionalismo deportivo [...] es cívico en la medida en que incluye a todos quienes se identifican con la selección nacional y [...] es opuesto al nacionalismo étnico que apela exclusivamente a los miembros de un mismo grupo cultural».

No obstante, en este estudio no nos abocaremos a discutir las implicancias y significados del equipo peruano en su modalidad «selección nacional» o al nacionalismo deportivo que apela la gran nación futbolística peruana. Como ya adelantamos, nos detendremos en el examen de uno de los clubes más tradicionales de ese país (Alianza Lima) que, dentro de los discursos deportivos revisados, cumplió un papel metonímico al atribuírsele significados vinculados con la propia nación peruana 5 .

En este punto es necesario aclarar esta importante distinción. El que un club como Alianza Lima (identidad local) haya sido transformado en representante de todo el Perú en la Copa Libertadores (identidad nacional) no es una operación para nada novedosa dentro de los discursos e intereses ideológicos del periodismo deportivo. Y no estamos hablando solo del caso peruano. Tal como ha demostrado magníficamente el argentino Frydenberg en su investigación sobre la gira del club Boca Juniors por Europa en 1925, este tipo de operaciones ideológicas están «claramente diseñadas e instrumentadas» (2003, p. 99). El hecho de que un club como Alianza —es decir, una parcialidad del Perú - sea convertido a través del discurso periodístico en un representante del fútbol peruano implicaría «una operación sobre la base de la existencia en el fútbol de fuertes rivalidades entre los clubes» (Frydenberg, 2003, p. 96), hecho que, desde luego, es invisibilizado por el periodismo deportivo dentro de sus retóricas nacionalistas.

Ya sabemos que esta operación no fue aleatoria. Además de ello, el Alianza Lima tiene gran arraigo dentro del Perú y ha forjado su prestigio sobre la base de un estilo de juego claramente definido, erigiéndose como uno de los más populares dentro de la sociedad peruana. Según estudiosos como Panfichi y Thieroldt, Alianza Lima «se caracteriza por un juego donde predomina la habilidad y la destreza con el balón. Se trata, sobre todo, de ganar, pero jugando 'bonito'. La superioridad debe quedar así claramente establecida» (2014, p. 7).

\footnotetext{
5 A diferencia de países como Argentina o Brasil, donde las identidades tribales son más fuertes y resulta impensado que, por ejemplo, un hincha de Rosario Central aliente a Boca Juniors porque «representa» internacionalmente a su país, en el caso peruano las cosas son un poco distintas. Esto se debe a una serie de factores, pero quizá el más importante son las discretas participaciones internacionales que han tenido los clubes peruanos, sobre todo en la Copa Libertadores. En ese sentido, es lugar común que la prensa deportiva peruana impulse un discurso «unificador» cada vez que cualquier equipo peruano participa en un torneo oficial de la Conmebol. De esta forma, el hincha de Universitario es llamado a respaldar al Alianza Lima y viceversa.
} 
Para muchos, este estilo de juego que podríamos denominar "virtuoso» del Alianza tiene sus orígenes en el equipo aliancista apodado como el «Rodillo Negro» ${ }^{6}$, que fue de gira por Chile y cosechó grandes resultados demostrando gran nivel y un estilo de juego caracterizado por la habilidad con el balón y técnica. En palabras del periodista deportivo Littman Gallo, aquellos muchachos del primer Alianza eran "palomillas, zambos, morenos, criollos, [y] no jugarían como los rudos y atléticos ingleses; poco a poco irían definiendo su propia manera de jugar al fútbol, nacida en las pistas de barrio, llena de habilidad y picardía, para darle una personalidad propia al juego aliancista y, por extensión, al fútbol que se practica[ba] en el Perú» (2018, p. 65). Aunque claro está, para alguien que no sea conocedor de este deporte, probablemente hablar de un juego "pícaro» le resulte un concepto demasiado gaseoso, o por lo menos abstracto.

Teniendo en cuenta este significado cultural atribuido desde su fundación al Alianza Lima, analizaremos el tratamiento informativo que tuvo su participación en la Copa Libertadores, específicamente el último partido ante la Universidad de Chile que significó su eliminación. Dicho torneo es considerado como una suerte de «test» en la evolución del nivel de los equipos peruanos, pues es lugar común decir — dentro de la prédica deportiva peruana- que el torneo doméstico tiene bajo nivel y el prestigio del país se pone verdaderamente en juego en el enfrentamiento antes sus pares de otros países sudamericanos. Por ello, no fue casualidad la enorme repercusión mediática que concitó el Alianza aquel año al llegar por primera vez a octavos de final desde que la Copa se disputa con 32 equipos en un formato de ocho grupos de cuatro integrantes.

Un dato no menor es que su rival en esta fase haya sido un equipo chileno: la Universidad de Chile. El historiador mexicano Lorenzo Meyer sostiene que el concepto de «relación especial» se usa en la literatura académica para describir a la relación entre dos estados nacionales o un conjunto de ellos que tienen «uno o más rasgos singulares que distinguen a la relación del conjunto de aquellas que cada una de las dos partes mantienen con el resto de los actores que forman la comunidad internacional» (1985, p. 15). Tomando en cuenta esto, podemos afirmar que la relación entre el Perú y Chile tiene esa característica que la hace «especial», es decir, que reviste un carácter singular, ello teniendo en cuenta una serie de características que

\footnotetext{
6 La alusión a la palabra "Rodillo» trae a la mente la idea de una verdadera "aplanadora», y esto se debió a los auspiciosos resultados obtenidos en la gira realizada por el club Alianza Lima en Chile entre noviembre y diciembre de 1935, una campaña en la cual disputó siete partidos, ganó seis y solo empató uno. Esta gira causó gran repercusión en la prensa limeña y fue tomada como una auténtica muestra de superioridad del balompié peruano por sobre el chileno. Lo de la palabra «Negro» se trató, evidentemente, de una referencia a la procedencia étnica de los jugadores peruanos.
} 
han generado tanto acercamiento como distanciamientos y que la academia se ha encargado de trabajar a ambos lados de la frontera.

Fue precisamente debido a este emparejamiento que los discursos futbolísticos peruanos se encargaron de presentar al equipo peruano - representante de la identidad peruana - sobre la base de una oposición al club del país sureño. $\mathrm{Y}$, a través de esta serie de estrategias, se evocaba nuevamente la vieja rivalidad entre ambos por alusiones a la guerra o a frases de corte nacionalista. El construir una identidad sobre la base al rechazo hacia el Otro (en este caso chileno) no es casualidad dentro de la prensa peruana, sino que nos remite a la teoría de la construcción de identidades deportivas formulada por Giulianotti (2001), quien postula que ellas pueden tomar formas semánticas o sintácticas. Las semánticas emergen cuando las personas se definen en base a lo que son (en términos individuales y colectivos), mientras que las sintácticas resultan del proceso de definirse por el rechazo enfático de lo que uno no es. De esta manera, en el fútbol, se naturalizan rivalidades deportivas, sociales y nacionales.

\section{Materiales y MÉtodo}

Para esta investigación, se seleccionaron las noticias sobre el partido de vuelta de octavos de final de la Copa Libertadores 2010 entre la Universidad de Chile y Alianza Lima (disputado en Santiago), específicamente las del día posterior a la eliminación del club peruano. El corpus está constituido por una combinación de diarios especializados en deportes (Depor, El Bocón y Líbero), medios generalistas (El Comercio, La República, Expreso, Perú.21, La Razón y La Primera) y tabloides ${ }^{7}$ (Trome, El Popular y Ajá), en todos los casos de circulación nacional. Estos diarios fueron escogidos debido a su prominencia nacional, su amplia cobertura en información deportiva y porque representan diferentes líneas editoriales, así como a una variedad de segmentos del mercado peruano de medios impresos. La mezcla entre especializados, generalistas y tabloides fue hecha debido a que se quería enriquecer el estudio con los diferentes estilos narrativos y usos lingüísticos que, en gran medida, determinan a su público lector. Se revisaron todas las ediciones (doce en total, una por periódico) y se realizó una clasificación temática, siguiendo el modelo de Análisis Crítico del Discurso (en adelante ACD) de Van Dijk (2003).

Asumiendo un enfoque multidisciplinar, Van Dijk parte de la triada discursocognición-sociedad para conceptualizar su modelo. Nuestro uso del concepto «discurso» está vinculado fundamentalmente a su uso como práctica social (Fairclough, 2003; Chouliaraki y Fairclough, 1999). Las prácticas sociales, en el sentido

\footnotetext{
7 O prensa popular/sensacionalista, según corresponda en otros países.
} 
en que se emplean en este artículo, se refieren a formas relativamente habituales de actividades sociales (escuchar una clase en la escuela, ver las noticias por televisión, acudir al estadio a un partido de fútbol, etc.). De hecho, cada práctica involucra la articulación de diversos elementos sociales dentro de una cotidianeidad estable, donde el discurso cumple un rol preponderante.

Sobre la cognición, Van Dijk (2003, p. 146) señala que implica tanto la cognición personal como la social, las creencias y los objetivos, así como las valoraciones y las emociones junto a otras estructuras que enmarca dentro de los procesos que denomina «mentales». En tanto, el eje denominado «sociedad» es entendido desde una dualidad: por un lado, consta de macroestructuras referidas a los significados globales, es decir, a los temas que las personas establecen mediante la producción y comprensión de los discursos; por el otro, se encuentran las microestructuras, que versan sobre los significados locales, esto es, el estudio específico del léxico, proposiciones, coherencia, entre otras.

Precisamente, nuestro estudio se desarrollará sobre la base de estos dos niveles. En una primera etapa examinamos las informaciones futbolísticas por medio de las estrategias macrosemánticas correspondientes al nivel global. De esta forma, identificamos los dos principales tópicos utilizados por la prensa deportiva peruana al momento de construir la eliminación de Alianza Lima de la Copa Libertadores: atribuir la derrota a factores externos (culpar al árbitro) y representar la eliminación del equipo peruano como una actuación heroica. Luego, con el análisis discursivo de las microestrategias (nivel léxico-textual), buscamos develar la forma en que la ideología nacionalista del periodismo deportivo peruano se materializa, influye y condiciona su discurso.

Una de las herramientas utilizadas por Van Dijk dentro ambos niveles de significado es el denominado "cuadrado ideológico" (Van Dijk, 1999), el cual permite estudiar la forma en que los discursos se polarizan bajo la representación del Nosotros y los Otros. La premisa de este instrumento se basa enfatizar lo positivo del Nosotros y lo negativo de los Otros, a la vez que se desenfatiza lo positivo de los Otros y lo negativo del Nosotros. Aplicado a nuestro caso de análisis, se pudo verificar la presencia de dos de las aristas del cuadrado: la prensa peruana enfatizó los aspectos positivos del Alianza Lima, a la vez que hizo lo propio con las características negativas de su rival, la Universidad de Chile. El cuadrado ideológico será clave para nuestra investigación, pues de esta forma podemos revelar la forma como la prensa peruana representó a los jugadores chilenos (y a Chile, por metonimia) a través de las narrativas futbolísticas sobre la derrota aliancista. Es decir, construyó la identidad nacional peruana (el Nosotros, encarnado en Alianza Lima) a través de una oposición sintáctica hacia los Otros (la Universidad de Chile y sus jugadores). 


\section{Principales hallazgos}

El club Alianza Lima logró su clasificación en el segundo lugar de su grupo (detrás de Estudiantes de La Plata) y tuvo como rival en los octavos de final a la Universidad de Chile. En el partido de vuelta, jugándose los 92 minutos, el club peruano superaba a la Universidad por 1-2 y con ese resultado se clasificaba para la siguiente fase. Fue en ese momento cuando ocurrió una acción que terminó con el gol de empate chileno, que les permitió a la postre lograr su clasificación. La jugada puede ser descrita como sigue: un futbolista del equipo chileno Montillo realiza un centro hacia el área peruana, la cual es despejada en medio de un tumulto de jugadores por el arquero aliancista Forsyth. Tras el rebote, la pelota le queda a Iturra, quien de un pase se la acomoda a su compañero Seymour, que remata violentamente hacia el área peruana. Lamentablemente para los intereses peruanos, el defensa paraguayo de Alianza Edgar González, en su intento por despejar el balón con la cabeza, la roza y termina por introducirla en su propio arco; es decir, un autogol. Resulta una verdadera paradoja que haya sido un paraguayo, arquetipo del buen juego aéreo, quien haya terminado por equivocarse en un despeje de cabeza.

Para los discursos de la prensa peruana, el gol debió ser anulado por un supuesto off side. La discusión se basaba en que entre González y Forsyth había algunos jugadores de la Universidad de Chile que habrían obstaculizado la visión del arquero peruano. La prensa peruana remarcó una situación particular: el juez de línea levantó su banderín señalando el aparente fuera de juego, pero luego se corrigió amedrentado, según los medios peruanos, por los jugadores y cuerpo técnico del equipo local. Aquí hay que tener presente un factor clave: el entrenador de la ' $U$ ' era el uruguayo Gerardo Pelusso, a su vez ex director técnico de los aliancistas, a quienes sacó campeones el año 2006. Este incidente causó tanta repercusión que incluso fue llamado "el gol de Pelusso» por la prensa chilena. A raíz de este hecho, el técnico uruguayo se ganó la animadversión de gran parte de la hinchada aliancista, sentimiento que permanece hasta la actualidad, aunque él afirme mantener su cariño por Alianza ${ }^{8}$.

Fue esta polémica decisión arbitral la que terminó por convertirse en uno de los principales argumentos de los discursos de la prensa deportiva peruana para representar discursivamente la eliminación del Alianza Lima como un hecho injusto. Tras el partido, fueron invisibilizadas las críticas al estilo de juego del equipo, a los

8 Cada vez que a Alianza Lima le toca visitar a equipos uruguayos por alguna competencia internacional, la prensa peruana suele entrevistar a Pelusso y el tema del partido de 2010 es evocado. En una de sus últimas entrevistas afirmó: «He recibido ingratitudes. Me tocó enfrentar a Alianza con la 'U' de Chile y me pusieron la cruz, como si hubiera despojado a Alianza de la Copa (Libertadores). Me resultó ingrata la devolución de muchos hinchas de Alianza. Si creen que es fácil salir campeones, entonces que vayan y salgan campeones, porque Alianza no campeona desde 2006, cuando dirigí al equipo» (Perú21.pe, 30 de agosto de 2015). 
errores defensivos y no se mencionaron los antecedentes inmediatos (el partido perdido de locales, por ejemplo) que también repercutieron en el resultado final. Este tipo de comentarios fueron hábilmente desenfatizados (porque debilitaban la posición aliancista) para dar prioridad al tópico de la decisión arbitral. Aquí no podemos obviar el hecho de que la terna arbitral haya sido ecuatoriana. En efecto, es de suponer que la exaltación expresa de dicha nacionalidad dentro de los discursos periodísticos es una estrategia para reforzar la idea de que aquel actor que nos estaría "perjudicando" (o, para la prensa deportiva, robando) sea un ciudadano del Ecuador, un país con el que "coincidentemente» nos une una historia de encuentros, pero mucho más de desencuentros, con tres guerras fratricidas entre ambos países.

Sumado a esto, el hecho de convalidar el gol del empate de la Universidad se convirtió en las enunciaciones deportivas también en soporte para la construcción de un discurso victimista sobre Alianza Lima y, extendiendo su alcance por metonimia, hacia todos los peruanos. Esta ligazón, creemos, no es casualidad, sino que se inserta en parte de lo que representa la tradición del club. Desde sus orígenes, Alianza Lima ha sido vinculado con una "cultura del sufrimiento" (Vich, 2002). Esto es, si bien dentro de la historia deportiva del club es posible hallar pasajes exitosos y de gloria, también hay muchos episodios de dolor constante, situaciones límite y momentos trágicos, y todos ellos han acompañado al club prácticamente desde su fundación. Por ejemplo, cuando en 1929 la Federación Peruana de Fútbol suspendió al club y separó a siete jugadores de la selección alegando que se negaron a participar en una serie de partidos amistosos para recaudar fondos para el viaje al Campeonato Sudamericano de ese año; también el hecho de que su ídolo máximo falleciera prematuramente por una enfermedad estigmatizada (no se sabe si fue tuberculosis o sífilis), estar dieciocho años sin campeonar, o quizá la más trágica de todas, el perder una generación completa de jugadores con la caída del Fokker en la mar de Ventanilla, y se pueden enumerando episodios de similar magnitud.

A continuación, empezaremos por analizar el primer tópico mediante el cual la prensa peruana retrató la eliminación de Alianza Lima de la Copa Libertadores.

\subsection{Atribuyendo el fracaso a factores externos: el árbitro (ecuatoriano)}

A pesar de poseer distintas líneas editoriales, la totalidad de medios deportivos en el Perú calificaron la eliminación de Alianza Lima como injusta, ya que, según estos, fue producto de un robo arbitral. Este fue el primer tópico que surgió luego de la revisión completa de nuestro corpus. El culpar al réferi por un resultado adverso en el partido no es una característica exclusiva de los peruanos: esto ocurre en la mayor parte de países donde se practica o se tiene al fútbol como el deporte más popular. Así también lo entiende Burgos (1999), quien, basándose en el caso mexicano, 
opina que debe empezarse a instalar en el aficionado una cultura que atienda menos al árbitro y más al propio juego.

A su vez, podemos subdividir esta macroproposición en dos aristas: la primera, referida a la construcción de la eliminación aliancista como «robo» y los adjetivos calificativos vertidos hacia el árbitro del partido, y una segunda dimensión, que se aboca a la representación del partido como una pesadilla o sueńo frustrado (con la posterior carga de trágica que ello conllevaría). Sobre la primera arista, la prensa peruana se valió de una variedad de metáforas para construir la derrota como si fuese un robo. Así, tenemos:

1. Cuando eres mejor, solo pueden mandarte a casa robándote. Metiéndote la mano al bolsillo como si así, tu bandera fuera más grande y tu juego mejor. Fue un robo, de esos desgraciados que el fútbol muestra de vez en cuando. Ese 2-2 clasificó a la U de Chile, pero dejó a Alianza tranquilo. Porque solo un robo, dos árbitros sin pantalones y una banca chilena que parecieron matones para presionar te pudieron ganar. Solo así pudieron (Perú.21 7/5/10).

2. Fue un robo a mano armada, de esos que ya hemos vivido más de una vez, pero que duelen como si fuera el primero. Al final, mucho premio para un equipo chileno mediocre y demasiado castigo para un cuadro íntimo que demostró su madera de grande y se retiró de la Copa con la frente en alto y el reconocimiento de todos (Libero 7/5/10).

3. Fue robo. Alianza estaba cerca de la hazańa. Ganaba 2-1. Faltaba un minuto de descuento y el árbitro ecuatoriano dio por válido un gol que su juez asistente vio en posición adelantada. Escándalo. Entonces, se armó la bronca. Protestaron todos en Alianza y todos sentimos que nos robaron, que Alianza debió ganar y clasificar a cuartos de final. Fue robo a mano armada, sin pistola, pero suficiente para matar a los blanquiazules (El Popular 7/5/10).

El término «robo» fue empleado con la connotación de una equivocación adrede para perjudicar al equipo peruano y eliminarlo de la competición, y no por un error humano involuntario producto de un hecho fortuito en el juego. Frases metafóricas como "meterte la mano al bolsillo» (1), «robo a mano armada» (2 y 3) y «matar» (3) son claras muestras de ello, pues ambas son de uso coloquial dentro del léxico peruano. Tradicionalmente, la metáfora es analizada como una figura literaria y es importante únicamente en el ámbito del lenguaje (como recurso estilístico), quedando al margen cualquier tipo de relación con el pensamiento o procesos de acción en las personas. Sin embargo, para autores como Lakoff y Johnson esta también tiene una relación —y muy importante, además — con la vida cotidiana y todo lo que nos rodea: «Nuestro sistema conceptual ordinario, en términos del cual pensamos y actuamos, es fundamentalmente de naturaleza metafórica» (1998, p. 39). Es decir, las metáforas funcionan a modo de mecanismos cognitivos con los que 
podemos estructurar nuestros pensamientos y acciones a través de la transparencia y comprobación de una cosa por otra.

Otra cuestión reveladora es la construcción de metonimias entre Alianza Lima y el público peruano, pues, como bien se muestra, se dice que el supuesto robo sufrido por el club peruano «ya lo hemos vivido más de una vez» (1) y «todos sentimos que nos robaron» (3). Este tipo de cláusulas, donde el periodista introduce su enunciado en modo elocutivo, permite construir un "nosotros» nacional que se ve reflejado en el accionar del Alianza Lima. Ese «nosotros», el pueblo peruano, también se vería afectado por el error arbitral que excluyó a Alianza de la Copa.

Ahora bien, también podríamos centrarnos en el hecho de que este énfasis en retratar la eliminación como un «robo arbitral» puede insertarse en una narrativa mayor: la del «jugamos como nunca, pero perdimos como siempre». O lo que es igual, la del «casi ganamos», pero "algo pasó» que nos impidió salir con la victoria. Esto, dentro de la historia del fútbol peruano, tiene un origen mítico claramente establecido: la participación de la selección de fútbol en los Juegos Olímpicos de Berlín en 1936. Dentro de la mitología deportiva local, se ha presentado el intempestivo retiro de la delegación peruana tras su partido contra Austria como una responsabilidad directa de Adolfo Hitler. A partir de ello, se han construido una serie de leyendas que colocan a los olímpicos peruanos como víctimas de un «robo" del gobierno nazi y a los dirigentes de la época como honorables caballeros por no aceptar que se repitiera el encuentro con los austriacos. No obstante, toda esta narrativa ha sido bien desmontada por el estudio de Arias Schereiber (2008), quien da cuenta de que quienes ordenaron la repetición del mencionado partido fueron en realidad una comisión de justicia de la propia FIFA.

Este es solo el ejemplo que inaugura el mito conformista que suele esbozar el periodismo peruano cuando nos topamos con un resultado adverso: "Casi ganamos, pero nos robaron el partido». Podríamos mencionar otros pasajes de gloria, pero efímera, como el buen arranque de la selección en el Campeonato Sudamericano de 1959 en Buenos Aires (empate con Brasil y triunfo ante Uruguay) para terminar empatando con Bolivia y perdiendo ante Paraguay, cayendo hasta un mezquino cuarto lugar. $\mathrm{O}$ incluso la excelente primera fase del Mundial 1978, y luego perder los tres partidos de la segunda, con una escandalosa goleada por 0-6 ante la Argentina.

Retomando el análisis discursivo, un segundo momento fue el ponderar su campaña como una gran hazaña y, dados los escasos logros deportivos en el Perú, construirlo como un gran sueño del cual, tras la abrupta salida de competencia, se convertía en una pesadilla. Junto a reflejar un discurso ciertamente fatalista, estas narrativas dan cuenta, en la terminología psicoanalítica lacaniana, de construcciones fantasmáticas que existen a partir de los temores y deseos dentro del sentido común de la cultura popular peruana. Como ha sido señalado acertadamente por 
Panfichi y Vich (2006, p.115) refiriéndose a la tragedia del Fokker del Alianza Lima, «la 'verdad' de las historias no está referida al hecho histórico en-sí-mismo, sino que ellas dan cuenta de las formas como los individuos procesan culturalmente algunos acontecimientos de su existencia». En nuestro caso de estudio, estos individuos son los periodistas deportivos. Veamos los siguientes ejemplos para verificarlo:

4. Todos de pie, todos aplaudiendo. El tiempo, con noventa minutos cumplidos, les decía que era hora de dormir y seguir sońando con la Copa, pero el árbitro sacó el arma para robar la más preciada fantasía y despertarlos con la bronca de haber perdido la ilusión (La República 7/5/10).

5. El robo descarado pudo más que el esfuerzo, la entrega y el amor por no querer perder. Alianza Lima clasificaba a cuartos de final de la Copa Libertadores, pero la actuación nefasta del árbitro ecuatoriano Carlos Vera convirtió su sueño en una pesadilla (Trome 7/5/10).

6. Fueron 111 minutos de sufrimiento, angustia y bronca. Una eternidad para el corazón de Gustavo Costas [DT de Alianza Lima], que ensució su traje y sus finos zapatos para pisar la cancha del Monumental donde le robaron la ilusión. Y es que el árbitro ecuatoriano Carlos Vera fue la mejor arma de la Universidad de Chile para clasificar al convalidar un gol polémico en el empate 2-2 que deja afuera a los íntimos de la Copa Libertadores (Ajá 7/5/10).

Si el árbitro es el agente que saca el arma "para robar la fantasía» (4) y hacer despertar a Alianza Lima del sueño que significaba su participación hasta ese momento en la copa, podríamos postular que la «verdad» (la veracidad del gol chileno o no) debe permanecer en la sombra, oculta, invisible, pues de lo contrario caerían los fundamentos que enaltecen la propia construcción épica de la campaña de Alianza que hizo la prensa peruana. De hecho, toda sociedad se funda en una fantasía que permite su sostenimiento y neutraliza las divergencias y antagonismos sociales (Zizek, 1999, p. 115), por lo que en este caso la fantasía que construye la prensa deportiva del país andino sugiere la representación de un Alianza Lima víctima de un fallo arbitral que lo perjudicó.

Fiel reflejo de este discurso que construye al equipo peruano como víctima es el análisis del sistema de transitividad, tanto en (5) como en (6). La transitividad es el sistema gramatical de recursos con los cuales construimos imágenes mentales de los eventos de la realidad y de los participantes en ellos. En este caso, el club Alianza Lima siempre se representa en voz pasiva, como sujeto paciente de las acciones del árbitro, quien funciona a modo de agente (ya sea por su fallo, que perjudica a Alianza, o por finiquitador de su sueño). Al representar de esta manera las acciones del partido, la prensa peruana erigió argumentos y los combinó con predicados que les otorgaban una interpretación particular de los hechos, ciertamente parcializada. 
Estas representaciones trágicas de la eliminación del Alianza Lima tienen un reverso, un lado que funciona a modo de suplemento y es el tema de manifestación tangible de frustración, enojo y pena de los actores vinculados con el club peruano (jugadores y director técnico). Tal como ha sido subrayado por Panfichi, el término tragedia en el mundo del fútbol «se refiere por lo general a un incidente de gran infortunio con enormes consecuencias emocionales en la comunidad de hinchas y seguidores» (2014, p. 210). Aun cuando el sociólogo describe un hecho cuantitativo más que uno cualitativo (el accidente aéreo del club aliancista de 1987 que cobró la vida de toda su plantilla), en el contexto de esta investigación podemos apropiarnos del término en el sentido en que también alrededor de la eliminación de Alianza en la Libertadores de 2010 se construyeron sendos imaginarios y representaciones discursivas que intentaron explicar tal fenómeno desde diferentes puntos de vista.

Tras la participación de Alianza Lima en la Libertadores, fueron construidos discursos desde el dolor, la pena e incluso el llanto que eran reflejo de una posición subjetiva de la prensa escrita peruana, que intentaba enaltecer la campaña de su equipo y humanizar a los protagonistas, quienes, en lugar de verse representados como humillados por derramar lágrimas tras la eliminación, fueron convertidos en jugadores comprometidos con la causa, orgullosos de su performance en el torneo y víctimas de un hecho ajeno a ellos ante el cual mostraban su rebeldía: el no querer mostrarse como derrotados y buscar algún argumento detrás de su salida de la copa. En este ámbito se utilizó la estrategia de la intertextualidad para traer a la polémica el testimonio de primera mano de los propios «afectados», los jugadores aliancistas. Así, observamos:

7. La impotencia y el llanto de Costas [DT de Alianza Lima] era conmovedor. No lo podía creer e indignado se abalanzó sobre el árbitro, quien impávido y con un cinismo único, se escudó en los carabineros para ocultar su fechoría (Libero 7/5/10).

8. Por su parte, Wilmer Aguirre [delantero de Alianza Lima] dijo sentirse destrozado porque les robaron un partido que tenía todo para ser calificado de histórico. «El árbitro clasificó a la U de Chile. Nos robaron. No es posible que nos pase esto, me duele bastante que un árbitro nos quite un resultado importante para nuestra historia», dijo el 'Zorrito' (El Bocón 7/5/10).

9. George Forsyth [arquero de Alianza Lima] y Jean Tragodara [volante de Alianza Lima] lloraron como niños la injusta eliminación de la Libertadores. Ambos lamentaron quedar fuera por culpa del árbitro. Esto es injusto, dijo el arquero con lágrimas en el rostro (Depor 7/5/10).

En los casos anteriormente citados (7, 8 y 9), los sustantivos impotencia, llanto y lágrimas forman parte de un mismo campo semántico asociado a la congoja luego de la eliminación del equipo aliancista. En el ámbito del fútbol, estos casos fisu- 
rarían la masculinidad hegemónica de un deporte asociado a la rudeza y virilidad, donde el discurso «natural» es no demostrar sentimientos de debilidad. No obstante, el llanto ante una derrota (más aún en el contexto de la que ocurrió con Alianza Lima) supone una excepción a la regla. Precisamente, las lágrimas en el campo de juego son representadas como un acto de carácter del futbolista, es decir, que se ha sentido afectado por el resultado adverso, le importa y buscará seguramente una revancha en el futuro próximo.

Se puede afirmar que se genera un vínculo de cercanía con el lector al traer a las crónicas deportivas el habla reportada de los protagonistas (en 8 y 9), quienes brindan testimonio en primera persona sobre los hechos ocurridos. De esta manera, identificamos la estrategia de la intertextualidad asociada a las narrativas sobre la eliminación de Alianza Lima: la voz de los protagonistas. Como bien señala Fairclough, la intertextualidad se refiere a la propiedad de los textos de remitir a elementos de otros textos anteriores, sumándose así a antiguos repertorios, que se transmiten y movilizan entre redes de textos parecidos o pueden ser empleados para la interpretación e invención de nuevos textos (1992, p.101). No obstante, lo revelador aquí es que solo se traen al discurso las declaraciones de los jugadores aliancistas, lo que evidentemente contribuye a potenciar su representación positiva en desmedro de los chilenos. Una selección que, desde luego, no se realiza por casualidad.

\subsection{Enfatizando lo positivo del Nosotros: una derrota «heroica»}

Junto a la atribución de factores externos a la derrota aliancista en la Copa, los enunciados deportivos peruanos también se encargaron de construir una representación que estableció una distinción entre el Nosotros (Alianza Lima) y los Otros (Universidad de Chile), la cual determinó el tipo de estructuras que contenía tales discursos. Como ya se indicó, entendemos al discurso como práctica social, en tanto construye una representación de la realidad y funciona como un instrumento de difusión y naturalización de ideologías y relaciones de poder. En ese proceso, evidentemente, subyacen creencias, intereses y pensamientos que determinan qué tipo de información es la que se brinda a los lectores (y cuál no) y también la forma en que esta se presenta en el discurso. En este apartado, intentaremos demostrar cómo los periodistas peruanos — en el caso de la eliminación de Alianza Lima— no pudieron mantenerse ajenos a sus creencias y subjetividades cuando redactaron las crónicas sobre el partido, lo que en el discurso periodístico reflejó una manera particular de entender la realidad desde su propia perspectiva como peruanos.

Esta representación del Nosotros contra los Otros tiene, claro está, un carácter ideológico. En todo discurso de este tipo podemos distinguir un enfrentamiento entre un grupo social y otro. El Nosotros representa al grupo con el cual el productor del discurso se identifica y comparte gran parte de otras formas de comportamiento 
social y de ver la realidad; los Otros, por el contrario, representan al grupo frente al cual el Nosotros se siente ajeno o distinto en tanto su modo particular de observar la realidad o de «administrar su goce» (Zizek, 1999, p. 47).

Ya puntualizamos que este enfrentamiento entre el Nosotros y los Otros en el discurso se manifiesta a través de la polarización de las características positivas conferidas al Nosotros y de las cualidades negativas atribuidas al Otro (Van Dijk, 2010, p. 80). A raíz de esta presentación de ambos tipos de características encontradas en la data de nuestro estudio, podemos echar mano de lo que Van Dijk denomina «cuadrado ideológico». Esta metaestrategia consiste, en términos sencillos, en resaltar lo positivo del Nosotros y lo negativo del Otro por medio de cuatro movimientos que son las aristas del cuadrado ideológico.

De acuerdo con la revisión de los diarios el día posterior al partido, se pudieron identificar ejemplos de las dos primeras aristas ${ }^{9}$. Esto quizá se deba al poco interés de la prensa escrita peruana por ahondar en los aspectos positivos referidos al equipo chileno, sino más bien resaltar sus características negativas, que abundaron dentro de los textos deportivos examinados. Refiriéndonos a la enfatización de lo positivo del Nosotros, los periodistas peruanos utilizaron dos grupos de estrategias: la predicación, agencia y selección léxica, y las metáforas bélicas, construyendo una dicotomía entre vencedores y vencidos.

El uso ideológico de la predicación se basa en la forma como los actores sociales son representados; en otras palabras, las cualidades (sean positivas o negativas) que se le asignan en el discurso. La agencia, por su parte, funciona de modo complementario a la predicación, pues se utiliza en los enunciados para responsabilizar al Otro de las acciones negativas y atribuir al Nosotros las positivas y, como apunta Van Dijk (2010, p. 82), puede servir también para desenfatizar o mitigar responsabilidad en el Nosotros para las acciones negativas. En las líneas siguientes, nos abocaremos a demostrar cómo ambas estrategias son utilizadas por la prensa peruana para elaborar una representación positiva del club Alianza Lima y sus jugadores (el Nosotros) por medio de la asociación permanente entre dicho club y acciones positivas, heroicas o dignas.

Junto a estas estrategias, como bien subraya Arrunátegui (2010, p. 442), podemos incluir a la selección léxica, pues es a través de la selección de piezas léxicas ciertamente convenientes para el Nosotros, que la predicación y la agencia pueden construir esta imagen positiva del Alianza Lima. Este hecho no es un dato menor, pues el quehacer periodístico implica necesariamente la selección y clasificación de la información: «Los hechos son una construcción del periodista, no existen por su cuenta, ni siquiera en la forma de las ideas al fondo de la cueva platónica, sino que

\footnotetext{
9 El enfatizar los positivo del Nosotros y el hacer hincapié en los aspectos negativos de los Otros.
} 
deben ser individualizados, darles un comienzo, un desarrollo y un final, ordenar jerárquicamente las distintas unidades de sentido que posean y, aún con el máximo desprendimiento intelectual del autor, son un puro ejercicio de subjetividad» (Bastenier, 2015). En los siguientes ejemplos, notamos cómo Alianza Lima o sus jugadores aparecen en el argumento como agente de predicados verbales que expresan acciones positivas, heroicas o dignas, en referencia a su eliminación de la Copa Libertadores:

10. La Libertadores no terminó para Alianza y va a perdurar por la gloria y la injusticia que vivió. Por la muestra de fútbol más espectacular en su pico de rendimiento, por sus golazos, por el asombro del continente y por la sensación de asalto que vivió anoche, incluso a mano armada por los carabineros chilenos. Es lo que debes sentir Alianza, de ti no se olvidarán (El Comercio 7/5/10).

11. La estadística dirá que los victorianos quedaron eliminados, pero la historia contará de un partido lleno de escándalo, con bronca de los peruanos defendiendo con uñas y dientes la vida lo que consideraban suyo. Sin arrugar, pese a que los locales estaban rodeados de carabineros, Libman, Vidal Sosa y otros reclamaron al juez su decisión (Trome $7 / 5 / 10)$.

12. Bien el 'Negro' González siendo de hierro, sacando pasto con sus pies y con la mala fortuna de haber sido él quien desvió la pelota que originó el pretexto del árbitro Vera para descalificar a los grones (El Comercio 7/5/10).

En estos ejemplos puede evidenciarse cómo la prensa peruana selecciona ciertos predicados verbales y determinados argumentos de connotación positiva o heroica y los enlaza en su discurso: "perdurar» (pred.) - «la gloria» (arg.), "peruanos» (pred.) «sin arrugar» (arg.) y "González» (pred.) - «mala fortuna», "pretexto del árbitro Vera» (arg.). Resulta claro que los discursos posicionan a Alianza Lima y a sus jugadores como los héroes del partido, a pesar de su eliminación. Ello, además de contribuir a construir su imagen positiva, los muestra como víctimas — una vez más— del infortunio («injusticia que vivió», «sensación de asalto que vivió», «rodeados de carabineros», «el pretexto del árbitro Vera para descalificar a los grones»).

Otra estrategia relevante dentro de la misma línea de representación (enfatizar lo positivo del Nosotros) que comulga con esta presentación «heroica» de los futbolistas peruanos es el uso de la metáfora bélico-militar. De acuerdo con Segura (2009, p. 69), este tipo de metáforas se refieren a «aquellos términos que tienen su significado primario en el campo semántico relativo a la milicia y que, más tarde, por un efecto de traslado de sentido, adquieren un significado particular en el ambiente del balompié». El uso de la terminología militar para articular el discurso del fútbol captura perfectamente la esencia de la peruanidad contemporánea: un sentido de sacrificio y rebeldía que se remonta hasta la derrota de la Guerra del Pacífico. Según la data revisada, la prensa peruana construyó su discurso bélico basándose en la memoria de aquella nefasta guerra, tal como se revela en los siguientes casos: 
13. Ni 45000 chilenos pudieron intimidar a este Alianza que salió a la cancha como si buscara recuperar Arica y Tarapacá. Lo habían repetido en la previa hasta el hartazgo: «No nos importa haber perdido en casa, porque nosotros demostramos que somos más que la U de Chile» (Depor 7/5/10).

14. Solo así [error arbitral] podían sacar de esta Copa a Alianza. A un equipo que aprendió de sus errores y que plantó la bandera peruana en medio de Santiago. El hincha blanquiazul debe llorar, pero no por la eliminación, sino de emoción por la valentía de sus jugadores (Depor 7/5/10).

15. Aunque la Copa se haya acabado [para Alianza Lima], en medio del dolor, de la injusticia, queda un equipo que regresa con honor de la guerra (Depor 7/5/10).

Manzano (2005) sostiene que durante el análisis del discurso las metáforas son de gran efecto, es decir, constituyen modelos lingüísticos que conectan con diferentes temas, como creencias, actitudes, valores, etc. En los ejemplos anteriores, el vínculo que construye la prensa peruana entre el partido de fútbol (que enfrenta a dos equipos peruano y chileno) y la guerra que, efectivamente, enfrentó a habitantes de dichos países en 1879 resulta evidente. Por ello es posible verificar un tipo de discurso nacionalista en ellos, cargado de una ideología que trabaja con la memoria histórica del Perú como "país amputado de territorios» por Chile ("Alianza salió a la cancha como si buscara recuperar Arica y Tarapacá»). De esta manera, el recuerdo de los territorios perdidos en la guerra se naturaliza en las prácticas discursivas de la prensa peruana como si fuese una revancha o una reclamación «justa» en favor de una posible devolución.

Un símbolo muy revelador dentro del uso de metáforas bélicas es el de la bandera. El "plantar la bandera peruana en medio de Santiago" (14) no solo es un recurso retórico provocador, sino que es el equivalente a una invasión o penetración dentro del territorio enemigo propiamente dicho. Como el Alianza Lima era visitante en aquel partido, el recurso de la bandera es presentado como prueba de que los peruanos, aun eliminados del torneo, pudieron causar mella en sus adversarios, devolviendo simbólicamente la «invasión» de las tropas chilenas en la Guerra del Pacífico. A este ejemplo podemos sumar la representación de la derrota como «honorable», ya que se afirma que el equipo aliancista «regresa con honor de la guerra» (15) a pesar de la derrota consumada. Al igual que en el enfrentamiento de hace casi dos siglos entre Perú y Chile, los del país andino también son construidos como derrotados, pero, como suele ocurrir en los discursos nacionalistas de este tipo, este fracaso es procesado en forma positiva en tanto se afirma que los futbolistas entregaron sus máximas energías y pelearon hasta el último minuto del encuentro, incluso siendo superiores para algunos. 


\subsection{Enfatizando lo negativo de los Otros}

Los principios analíticos que se discutirán a continuación están referidos a la enfatización de las características negativas del Otro. Para nuestro caso, la prensa peruana presenta a este Otro como la Universidad de Chile y sus jugadores, para luego, a través de un proceso metonímico, atribuirles esta otredad a todos los chilenos. Las estrategias que revisaremos en este apartado serán la predicación, agencia y selección léxica junto con la modalidad. Empezando con la predicación, tenemos los siguientes textos:

16. Los íntimos sabían que, con fútbol, con talento, se podía dar vuelta al 1-0 en Matute y dejar en el camino a un equipo tan mezquino como el chileno. Y jugó así. $\mathrm{O}$ mejor, porque al buen toque de balón le sumó empuje, coraje y harto huevo (Depor 7/5/10).

17. Alianza Lima hizo todo lo necesario para estar entre los ocho mejores de la región. Jugó con personalidad, aplomo y brillantez ante un equipo 'chuncho ${ }^{10}$ que se sorprendió con la agresividad de Gustavo Costas [técnico de Alianza Lima]. No tardó el equipo íntimo en adueñarse del partido, pareciendo local en el Monumental (La Razón 7/5/10).

18. La derrota de Alianza fue injusta. Besaba la gloria y se le esfumó de las manos. Jugó un excelente primer tiempo, aunque decayó en el segundo, pese a ello fue más que su timorato rival que jugó asustado, sin ideas y que tuvo que soportar la mayor parte del partido el mejor toque y funcionamiento de los peruanos $(E l$ Bocón 7/5/10).

Recordando que la predicación establece el ejercicio de etiquetar a los actores como más o menos positivos o negativos a través de una atribución o evaluación en el discurso, vemos en los casos presentados que, una vez más, gran parte de las acciones y cualidades negativas son vinculadas directamente a los Otros, ya sea calificándolos a ellos mismos o a las acciones que estos realizan. De esta forma, el equipo de la Universidad de Chile es calificado como «mezquino» (16), «chuncho» y «sorprendido por la agresividad de Gustavo Costas» (17) y «timorato, asustado y sin ideas» (18).

Aquí nos es útil nuevamente el sistema de la transitividad ya que en las cláusulas donde se menciona a la Universidad de Chile, esta es representada de forma pasiva, como sujeto paciente. Ello ayuda a reflejar un aparente dominio (futbolístico) de Alianza Lima por sobre su rival que, dada la eliminación peruana, podría resultar contradictorio y muy subjetivo. Así en (16) Alianza Lima «deja en el camino» al "mezquino equipo chileno», en (17) es el cuadro universitario quien «se sorprende» de la agresividad de los peruanos, mientras que en (18) la Universidad de Chile «tuvo que soportar la mayor parte del partido el mejor toque y funcionamiento de los peruanos».

${ }_{10}$ Jerga peruana que se refiere a alguien demasiado parco o tímido. 
Por otro lado, con la intención de seguir ensalzando lo negativo del equipo rival, la prensa peruana modalizó las cláusulas referidas al gol del empate final que a la postre le dio la clasificación a la Universidad de Chile. La modalidad es una categoría gramatical que se relaciona con el grado de certeza que tiene el emisor con respecto al contenido de un enunciado. Así, este recurso puede expresar un amplio campo de matices semánticos según la actitud del emisor sobre su enunciado y hacia su interlocutor. Las clasificaciones de la modalidad varían de un autor a otro. Para el caso de la presente investigación, me guío bajo el enfoque de Halliday (1994), quien distingue entre dos tipos: epistémica y deóntica. La modalidad epistémica expresa el grado de probabilidad o de habitualidad del enunciado sentenciado por el emisor, mientras que la modalidad deóntica marca una obligación o necesidad, además de señalar juicios de valor del hablante sobre cómo deberían comportarse las personas. Dentro de los textos revisados, pudimos encontrar ejemplos de ambos casos, tal como se refleja a continuación:

22. Pero una vez más parece que los equipos peruanos tienen un karma que no los deja saborear la victoria y en los minutos de reposición llegó el tanto polémico de la Universidad de Chile (La Primera 7/5/10).

23. El árbitro Carlos Vera, que debe impartir justicia y pasar inadvertido, fue el que se robó todos los flashes de la noche. Pero no fue lo único que se llevó, también birló la esperanza de Alianza Lima que vio como un gol que debió ser anulado porque delanteros de la $\mathrm{U}$ de Chile estaban adelantados (en posición activa, obstruyendo la vista de Forsyth) era cobrado cuando el reloj decía que el tiempo del partido estaba culminado (La República 7/5/10).

24. Por más que el balón haya chocado en la testa del Negro González, eso no habilita la acción para que Carlos Vera, el incapaz ecuatoriano, le diera validez al gol de la vergüenza de los mapochinos (El Bocón 7/5/10).

El destino de los equipos peruanos aparece modalizado epistémicamente con el marcador «parece» (22). A través de esta cláusula los periodistas peruanos dan a entender que la eliminación aliancista sería fruto de una calamidad siempre ajena a sus circunstancias, lo que evidentemente mitiga la responsabilidad por la derrota al cuadro limeño: no se critica ni cuestiona en ningún momento su funcionamiento futbolístico como evidencia de su salida de la Copa Libertadores. Contrario a ello, el tanto convalidado a la Universidad de Chile —que supuso su clasificación — sí es puesto en duda a través de distintos adjetivos calificativos: «tanto polémico» (22) y "gol de la vergüenza» (24). Este ejercicio de cuestionar el gol chileno representándolo desde un punto de vista negativo - es decir, revistiendo de un halo de duda su legitimidad - ayuda a construir la imagen positiva del propio Alianza Lima y brinda a los lectores una visión parcializada de las acciones de juego. 
En cuanto a la modalidad deóntica, funciona con el mismo propósito: legitimar la posición aliancista desmereciendo el accionar de la U de Chile. En el caso (23), el marcador modal «debió ser» refleja que para la prensa peruana el gol de empate chileno fue ilegítimo desde todo punto de vista (incluso ensayan una explicación al respecto en 23 y 24). Lo revelador es que no se recurre a ningún tipo de experto en el reglamento (algún árbitro neutral para que juzgue la jugada), sino que son los propios periodistas peruanos lo que se atribuyen este trabajo de manera claramente parcializada.

\section{A MODO DE CONCLUSIÓN}

El objetivo de este artículo era llevar a cabo un análisis sobre las principales informaciones deportivas que se construyeron alrededor de la eliminación del club Alianza Lima de la Copa Libertadores 2010 y cómo ello generó diversas representaciones sobre la identidad nacional peruana. El estudio realizado ha arrojado resultados bastante claros. La prensa deportiva elaboró dos grandes imágenes sobre la derrota: la representación de la eliminación aliancista como consecuencia del infortunio (error arbitral) y, al mismo tiempo, el hecho de enaltecerla a través del movimiento de dos aristas del cuadrado ideológico: ensalzar lo positivo del Nosotros y enfatizar lo negativo de los Otros. Se ha podido ver, a través del examen de las diversas estrategias discursivas que se han presentado, cómo el discurso de la prensa deportiva peruana construyó una dicotomía Nosotros-Ellos sobre la base de un proceso metonímico consistente en construir una ligazón entre Alianza Lima y la idea de nación peruana, lo mismo para el caso de su rival chileno y el país austral.

Por otro lado, debemos incidir en el hecho de que escribir durante la estela de una Copa Libertadores, en la que la cobertura mediática peruana destacó con mayor frecuencia reacciones emocionales significativas hacia sus equipos nacionales, proporciona un punto de vista interesante para evaluar las representaciones analizadas aquí. La dicotomía de las reacciones periodísticas encontradas en nuestra muestra sugiere que la pasión por el fútbol en suelo peruano no es una representación completamente nueva, incluso si su grado de énfasis cambia según los vaivenes o desventuras de sus representativos en las competencias internacionales.

Los discursos acerca de las naciones, a pesar de las diferencias sustantivas, comparten una estructura similar. Todos afirman que cada nación es distinta, única y excepcional como parte de la articulación de la unidad interna y la diferencia externa (Calhoun, 1997). La reputación creada a través del deporte ofrece un mecanismo particularmente poderoso para especificar esta afirmación (Lechner, 2007). Aunque para muchos países la afirmación de la singularidad nacional a través del fútbol implica la articulación de un estilo de juego particular o el atractivo universal del deporte, en el 
Perú implica, además, estipular el significado ambivalente que se atribuye al fútbol a través de la comparación con el vecino del sur: Chile. Desde temprano en el siglo XX, el país austral se fue erigiendo dentro de la narrativa periodística limeña como el gran rival, tanto por razones geográficas, nivel de juego y diferencias en el estilo que, de alguna manera, «no podían coexistir con comodidad, de modo que, inevitablemente, cuando se encontraban, surgía el conflicto» (Wilson, 2017, p. 66).

Dicho esto, debemos resaltar la relevancia de los periódicos como material relevante y fuente para investigadores de diversas áreas (sociología, historia, comunicación, educación física, entre otros) para estudiar el tema de la construcción de la nación. Por lo tanto, reflexionar sobre el papel de la prensa deportiva como elemento constitutivo de la cultura es fundamental para que podamos observar cómo los periódicos ratifican y construyen mitos y discursos de identidad, que, a pesar de la objetividad periodística, son uno de los pilares de la profesión.

\section{REFERENCIAS}

Anderson, B. (1993). Comunidades imaginadas. México, D. F.: Fondo de Cultura Económica. Arias Schereiber, L. (2008). Berlín, 1936: la verdadera historia de los olímpicos peruanos. En A. Panfichi (ed.), Ese gol existe. Una mirada al Perú a través del fútbol (pp. 135153). Lima: Fondo Editorial de la PUCP.

Bhabha, H. (2010). Nación y narración. Buenos Aires: Siglo XXI.

Bromberger, C. (1994) La pasión futbolística y la Copa del Mundo: ¿por qué tanto ruido y tanta furia? En J. Sudgen y A. Tomlinson (eds.), Hosts and Champions. Arena: Aldershot.

Burgos, J. (1999). Culpar al árbitro. Nexos. Recuperado de http://www.nexos.com. $\mathrm{mx} /$ ?p=9438 [fecha de consulta 29 de noviembre de 2016].

Calhoun, C. (1997). Nationalism. Minneapolis: University of Minnesota Press.

Chatterjee, P. (2007). La nación en tiempo heterogéneo. Lima: IEP.

CPI (2009). Estudio de opinión pública a nivel Perú urbano sobre deportes. Lima: CPI.

Chouliaraki, L. y Fairclough, N. (1999). Discourse in Late Modernity: Re-Thinking Critical Discourse Analysis. Edinburgh: Edinburgh University Press.

Elias, N. (1992). Introducción. En N. Elias y E. Dunning, Deporte y ocio en el proceso de la civilización (pp. 31-81). Madrid: Fondo de Cultura Económica.

Fairclough, N. (1992). Discourse and Social Change. Cambridge: Polity Press.

Frydenberg, J. (2003). Boca Juniors en Europa: el diario Crítica y el primer nacionalismo deportivo argentino. História: Questôes \& Debates, 39, 91-120.

Gallo, L. (2018). Abriendo juego. Lima, Perú: Autor-editor.

Giulianotti, R. (2001). Constructing Social Identities: Exploring the Structured Relations of Football Rivalries. En G. Armstrong y R. Giulianotti (eds.), Fear and Loathing in World Football (pp. 267-279). Oxford: Berg.

Halliday, M. (1994). An introduction of functional grammar. Londres: Arnold. 
Hobsbawm, E. (1990). Nations and Nationalism since 1780. Cambridge: Cambridge University Press.

Lakoff, G. y Johnson, M. (1998). Metáforas de la vida cotidiana. Madrid: Cátedra.

Lechner, F. (2007). Imagined communities in the global game: Soccer and the development of Dutch national identity. Global Networks, 7, 192-229.

Manzano, V. (2005). Introducción al análisis del discurso. Recuperado de http://www.aloj. us.es/vmanzano/docencia/metodos/discurso.pdf

Meyer, L. (1985). México-Estados Unidos: lo especial de una relación. En M. García y Gustavo Vega (eds.), México-Estados Unidos 1984 (pp. 15-30). México, D. F.: El Colegio de México.

Pahuacho, A. (2014). El tópico sacrificial en los discursos de la prensa deportiva en el Perú. El caso del futbolista Paolo Guerrero. Correspondencias \& Análisis (4), 153-175.

Panfichi, A. y Thieroldt, J. (2014). Clubes y barras en Perú: Alianza Lima y Universitario de Deportes. Esporte e Sociedade, 9(24), 1-16.

Panfichi, A. y Vich, V. (2006). Rumores y fantasías sociales. La tragedia de Alianza Lima 1987. Íconos, revista de Ciencias Sociales, 25, 111-121.

Panfichi, A. (2014). Un solo corazón. La tragedia de Alianza Lima y la solidaridad del Colo Colo. En D. Parodi y S. González, Las historias que nos unen. 21 relatos para la integración entre Perú y Chile (pp. 209-217). Lima: Fondo Editorial PUCP.

Panfichi, A. (19 de octubre de 2017). El nacionalismo deportivo. El Comercio. Recuperadodehttps://elcomercio.pe/opinion/colaboradores/nacionalismo-deportivoaldo-panfichi-noticia-466829-noticia/?ref=ecr

Quiroga, A. (2014). Goles y banderas. Fútbol e identidades nacionales en España. Madrid: Marcial Pons.

Rowe, D. (2004). Sport, culture and the media: the unruly Trinity. Londres: The Open University Press.

Segura, G. (2009). Prepara, apunta, dispara... fusila al portero. La metáfora bélica en el fútbol, Káñina, Revista de Artes y Letras, XXXIII, 67-74.

SEPP (2013). Estudio de lectoría de diarios y revistas en Lima Metropolitana y provincias. Periodo: noviembre 2012 - octubre 2013.

Vich, V. (2002). Alianza Lima y la cultura del sufrimiento. En L. Millones, A. Panfichi y V. Vich (eds.), En el corazón del pueblo. Pasión y gloria de Alianza Lima 1901-2001 (pp. 129-143). Lima: Fondo Editorial del Congreso de la República.

Van Dijk, T. (1999). Estructuras ideológicas del discurso. En T. Van Dijk (ed.), Ideología. Una aproximación multidisciplinaria (pp. 328-345). Barcelona: Gedisa.

Van Dijk, T. (2003). Ideología y discurso. Barcelona: Ariel.

Van Dijk, T. (2010). Análisis del discurso del racismo. Crítica y Emancipación (2)3, 65-94.

Villena, S. (1998). El fútbol como ritual nacionalista. Ecuador Debate, 43, 90-107.

Wilson, J. (2017). La pirámide invertida. Buenos Aires: Debate.

Wood, D. (2008). Fútbol, cultura e identidad en el Perú. En A. Panfichi (ed.), Ese gol existe. Una mirada al Perú a través del fútbol (pp. 231-250). Lima: Fondo Editorial PUCP.

Zizek, S. (1999). El acoso de las fantasias. México, D. F.: Siglo XXI. 